VOLUME 8

Design Principles

and Practices

An International Journal - Annual Review

Design as Relational Discipline

LOREDANA DI LUCCHIO 
DESIGN PRINCIPLES AND PRACTICES: AN INTERNATIONAL JOURNAL — ANNUAL REVIEW www.designprinciplesandpractices.com

First published in 2015 in Champaign, Illinois, USA

by Common Ground Publishing

University of Illinois Research Park

2001 South First St, Suite 202

Champaign, IL 61820 USA

www.CommonGroundPublishing.com

ISSN: $1833-1874$

(C) 2015 (individual papers), the author(s)

(C) 2015 (selection and editorial matter) Common Ground

All rights reserved. Apart from fair dealing for the purposes of study, research, criticism or review as permitted under the applicable copyright legislation, no part of this work may be reproduced by any process without written permission from the publisher. For permissions and other inquiries, please contact

$<$ cg-support@commongroundpublishing.com>.

Design Principles and Practices: An International Journal - Annual Review is a peer-reviewed scholarly journal. 


\title{
Design as Relational Discipline
}

\author{
Loredana Di Lucchio, Sapienza Università di Roma, Italy
}

\begin{abstract}
Today, more than in the recent past, each branch of knowledge has developed and continues to experiment with specific models of the relationship between knowledge and society. In particular, in their roles as "producers" of education, the various disciplines act in line with the rationale of supply and demand. They try to carve out specific identities on the "market" of education and research. According to this aim, the main academic efforts of the present day seem to be focused on new didactic approaches, innovative programs, and new fields of knowledge. Design is highly involved in these efforts, and it shifts its attention from the results of education to the processes of learning and teaching.
\end{abstract}

Keywords: Design Education, Design Knowledge, Disciplinary Boundaries

$\mathrm{T}$ This new edition of Design Principles and Practices: An International Journal - Annual Review collects papers which offer us interesting stimuli for reflection on design not simply as professional or academic field, but as knowledge.

All these papers report some original didactic experiences during which diverse and quite innovative methods have been developed and applied. Moreover, this is true not in one specific area of design but (despite the small number of papers) in several of the most prominent ones: product design, communication design, and architectural design.

Upon reading these papers, some common features emerge: 1) the start point of all of them is the need to improve the design approach in their specific design fields based on a new disciplinary perspective; 2) the main effort is to find, in other fields of knowledge, possible useful tools to be transferred to the design field; 3) they applied a new teaching approach in order to measure the results of this transfer.

Despite the obvious differences, but considering these common features, some important questions emerge: Why is it so important in design fields to search for new methods and approaches? Why, in design fields, does academic effort seem focused more on methods than on results? Is design, perhaps, more a matter of process than a matter of products?

\section{The Features of Design Knowledge}

In order to try to reply to these questions, it could be useful to reflect on the role of design, as an academic discipline, within the contemporary cultural and scientific scenario.

From a cultural point of view, the need is strongly emerging in our time to reinterpret the roles of the various forms of knowledge and their capacities to create innovation, and therefore progress (in the sense of moving forward).

In fact, if a plural model of knowledge was the basis of Modernity, today we are seeing the collapse of all disciplinary notions while the epistemic boundaries are less and less clear.

The renowned definition of "liquid modernity" (Bauman 2000) is perfectly suitable to describe this scenario. Bauman said that social forms and institutions no longer have enough time to solidify and cannot serve as frames of reference for human actions and long-term life plans. In the same way, new knowledge no longer has enough time to solidify, and it runs out in a quick overlap of information, thinking, and statements.

Design emerged in the 1900s and it established itself as a scientific discipline in the second half of the century. We can agree that design was born in a "solid" world. In addition, for a long time, design was able to create conceptual and operative tools to act at a material level: in spaces, on objects, and with visual and tactile codes.

Design Principles and Practices: An International Journal-Annual Review 
Design can be considered a truly contemporary profession and, due to its "young" cultural history, it is dramatically positioned in the heart of the contemporary knowledge collapse.

Therefore, design is, in itself, a fluid knowledge that moves itself in a constant alteration of its boundaries and methods.

These alterations are reflected in educational models more than in professional practice, meaning that it is still difficult to identify design as a genuine branch of knowledge.

To teach something which is fluid means to use fluid approaches because it is impossible to search for and find and write fixed formulas. Furthermore, it is difficult to use fixed formulas in a fluid context to reach a predicted goal.

The result is a continuous redefinition of disciplinary statements, for design and all fields of knowledge. This redefinition is especially focused on the impact of knowledge on society (Appadurai 2000). In fact, in the face of socio-economic crises like the one we have been experiencing in recent years, the role of training and research is scrutinized and judged for its ability to trigger real positive impact.

The biggest question seems to be whether it is possible for design to offer "useful" research to society and, in particular, to offer "useful" knowledge to guide future societies.

This is a very complex question if we consider that the shattering of the great dream of positivist consumerism has opened several operative scenarios to the figure of the designer.

In particular, faced with the natural limits of environmental sustainability, design activities are also complex and increasingly multi-skilled. Making products now entails a very broad range of phenomena, including information, artifacts, activities, services, and policies, as well as systems and environments.

\section{The Competences for Design Education}

In parallel, teaching in the field of design no longer has an established structure. The very discipline of design became a way to generate innovative learning forms, consistent with new knowledge.

However, this is not so new; the "discovery of the design discipline" during the twentieth century, which culminated in the introduction of academic training programs, was not a simple step forward in the tradition of theoretical learning on which universities have historically been founded (Buchanan 1992).

Therefore, to discuss the methods of academic training programs in design means to open a reflection on two matters. The first concerns laying down internal rules for its practice. The second involves comprehending its external relations with cultural, social, and production systems.

The first cause for reflection has been an intrinsic part of this discipline since it first emerged, and it could be summed up with the question, "What does design do?" This question was evident in the dichotomy opened by the Arts and Crafts movement, in the promotional work of the Deutscher Werkbund, as well as in the Bauhaus' institutive commitment to training. And, moving forward to the 1960s and 1970s, the same debate was reborn in Italy in order to clearly outline the cultural role played by design in the construction of social identity (Branzi 1999).

The question, "What is design?" expresses the second cause for reflection, following the drastic upheaval of paradigms which has affected every branch of knowledge in post-industrial society.

As a result, all those who are responsible for providing knowledge have tried their hands at proposals, experiences, and actions. In short, training in the field of design has found itself not only at the heart of the contemporary collapse of knowledge, but with the urgent need to clarify in which of the two famous cultures described by C. P. Snow half a century ago it belongs (1959). 
The "small" picture that emerges from the selected papers is inevitably varied. The papers discuss three eduational frameworks: one focused on foundational learning, one focused on specialized training, and the last on research training. The educational models for the first and the second frameworks have close ties to the professional environment, with "design projects" that largely deal with technical and functional issues. These activities involve the collaboration and support of external producers such as professionals, companies, and institutions. In the case of the third framework, there is a sort of amalgam of knowledge. The focus on design no longer considers it to be an activity concerning material elements, but rather one that concentrates on the immaterial—not simply on services, but on actually creating new social behavior.

Transversely, it is possible to identify two principal directions of these didactic projects.

In the first direction, the didactic methods are based on practices from the social disciplines, which are more concerned with the observation of results than action; the focus is on the consequences of the behaviors of people rather than the functional performance of objects. In the other direction, the didactic projects are more closely related to engineering disciplines, which study and experiment with technologies and processes in the constant drive for innovation. This specific feature of design research-lying in between the humanities/social fields and the scientific/technological fields - can be defined as a sort of symbiotic state compared to other disciplines.

Therefore, in contrast to other disciplines, we can't describe design as an orthodox academic activity. This is why one of the urgent goals for the academic community is to imagine new and suitable teaching approaches. If we want to be operative critics within this "on the move" reality, we have to find a way to bring forth positive contributions.

In particular, a trans-disciplinary training in design is bringing into consideration any possible links with the contents of the other disciplines. Design education needs to propose a new procedural form based on scientific methods, evaluations, and feedback. This is because only a research-driven design guarantees to generate new knowledge.

In design, the rigorous attention to new methods and approaches able to respond to the contemporary collapse of knowledge recalls the five key-competences of education defined by the sociologist Oskar Negt at the beginning of 1970s (1975). These key-competences are: 1) Competence of Identity, to know our social and cultural history; 2) Competence of Justice, to know the relationships between the powers in society; 3) Competence of Ecology, to evaluate the future consequences of present actions; 4) Competence of History, to know design history; 5) Competence of Technology, to know and evaluate the quality and possibilities of the system. According to the Negt theory, it seems that the academic community of design must now recognize the need for interdisciplinary links between design and other fields of knowledge. This is because design seems unable to explore, as well as to understand, influence, and modify, the various Competences defined by Negt.

In this way, and according to the experiences described in the selected papers, design can be defined as a relational discipline.

\section{REFERENCES}

Appadurai, Arjun. 2000. "Grassroots Globalization and the Research Imagination." Public Culture 12 (1): 1-19.

Bauman, Zygmunt. 2000. Liquid Modernity. Cambridge: Polity.

Branzi, Andrea. 1999. Introduzione al Design Italiano: Una Modernità Incompleta (Introduction to Italian Design: An Incomplete Modernity). Milan: Baldini and Castaldi.

Buchanan, Richard. 1992. "Wicked Problems in Design Thinking." Design Issues 8 (2): 5-21. 
Negt, Oskar. 1975. Soziologische Phantasie und exemplarisches Lernen. Zur Theorie und Praxis der Arbeiterbildung (Sociological Imagination and Exemplary Learning: On the Theory and Practice of Workers' Education), 6th ed. Frankfurt am Main: Europäische Verlagsanstalt.

Snow, Charles Percy. 1959. The Two Cultures and the Scientific Revolution. Cambridge: Cambridge University Press.

\section{ABOUT THE AUTHOR}

Loredana Di Lucchio: Researcher and Professor, Department of Planning, Design, Technology of Architecture, Sapienza Università di Roma, Rome, Italy 
Design Principles and Practices: An International Journal - Annual Review explores the meaning and purpose of "design", as well as speaking in grounded ways about the task of design and the use of designed artifacts. The resulting conversations weave between the theoretical and the empirical, research and application, market pragmatics and social idealism.

In professional and disciplinary terms, the journal traverses a broad sweep to construct a transdisciplinary dialogue which encompasses the perspectives and practices of: anthropology, architecture, art, artificial intelligence, business, cognitive science, communication studies, computer science, cultural studies, design studies, education, e-learning, engineering, ergonomics, fashion, graphic design, history, information systems, industrial design, industrial engineering, instructional design, interior design, interaction design, interface design, journalism, landscape architecture, law, linguistics and semiotics, management, media and entertainment, psychology, sociology, software engineering, technical communication, telecommunications, urban planning and visual design.
Design Principles and Practices: An International Journal - Annual Review, consists of articles considered to be of wide interest across the field. Six thematically focused journals also serve this knowledge community:

- The International Journal of Design Education

- The International Journal of Design in Society

- The International Journal of Designed Objects

- The International Journal of Visual Design

- The International Journal of Design Management and Professional Practice

- The International Journal of Architectonic, Spatial, and Environmental Design

Design Principles and Practices: An International Journal - Annual Review, is a peer-reviewed scholarly journal. 